\title{
Effect of Soil Resistivity Measurement on the Safe Design of Grounding Systems
}

\author{
Vasilios P. Androvitsaneas * (D), Katerina D. Damianaki, Christos A. Christodoulou and \\ Ioannis F. Gonos 1
}

High Voltage Laboratory, School of Electrical and Computer Engineering, National Technical University of Athens, 9 Iroon Politechniou Str., Zografou Campus, GR15780 Athens, Greece;

katiadamianaky@msn.com (K.D.D.); christ_fth@yahoo.gr (C.A.C.); igonos@cs.ntua.gr (I.F.G.)

* Correspondence: v.andro@mail.ntua.gr; Tel.: +30-210-772-2523

Received: 14 April 2020; Accepted: 15 June 2020; Published: 18 June 2020

check for updates

\begin{abstract}
A prerequisite for the proper and safe designing of a grounding system is the full knowledge of the ground structure in the terrain of installation. Through soil resistivity measurements, engineers are able to illustrate the ground profile, which constitutes the most significant parameter for the design of a grounding system and for determining the maximum permissible limits of step and touch voltages. This paper highlights the high importance and necessity for engineers to choose the proper measurement axes of soil resistivity in the terrain of interest and to choose suitable measurement depths, as well the combination of axes for the final determination of the ground profile. The variance of soil resistivity values, as a function of axis distance and the impact of axis placement on determining the uncertainty of measurements, is also analyzed in detail in this study. Furthermore, this work studies the value variance of step and touch voltages as a function of measurement axes, considering two- and three-layer soil models, based on soil resistivity field measurements performed at the university campus. Therefore, the proper and premeditated measurement of soil resistivity, particularly in anisotropic ground, is proved to be of major importance for the full designing of a safe grounding system.
\end{abstract}

Keywords: grounding system; soil resistivity; soil models; step voltage; touch voltage; uncertainty of measurement

\section{Introduction}

A grounding system is a system of horizontal and vertical ground electrodes consisting of a number of interconnected bare metallic conductors imbedded into the earth in a specific area, which provides a conducting connection for electric equipment and any metallic structure to the earth, or to some conducting body of relatively large size that serves in place of the earth [1].

The main objective of a grounding system is the collection, drainage and dissipation of fault currents into the earth, through a conductive route of minimum possible resistance in the shortest possible time. The proper design and construction of a grounding system aims for the full satisfaction of these demands, in an effort to control ground potential rise (GPR), and to restrict the potential gradients under the maximum permissible limits, in an efficient way. This fact is the key point for the safety of people and the integrity of equipment, which can otherwise be put in serious jeopardy. Moreover, the efficiency of a grounding system contributes significantly and successfully to short response times and to the immediate activation of protection devices, resulting in the full and effective protection of people and facilities.

An important parameter for assessing the efficiency of a grounding system, concerning the safe dissipation of fault currents into the earth and the effective limitation of developing step and 
touch voltages, is the ground resistance of these systems $R_{g}$, i.e., the resistance between a ground electrode, grid or system and the remote earth, where the remote earth is a theoretical concept that refers to a ground electrode of zero impedance, placed an infinite distance away from the ground under consideration [2]. In fact, there are reports in the international literature investigating and evaluating what impact the distances and the arrangements of the probes and leads involved in the measurement may have on the accuracy of ground resistance measurement and the errors they can cause $[3,4]$. Furthermore, step voltage $E_{s}$ is defined as the difference in earth surface potential that could be experienced by a person bridging a distance of $1 \mathrm{~m}$ with his feet, without contacting any grounded structure, and touch voltage $E_{t}$ is the difference between the GPR of a grounding system and the surface potential at the place where a person could be standing while having a hand in contact with a grounded structure at the same time [2].

In general, the lowest possible resistance value is pursued for all cases of grounding systems, both in small- and large-scale electric facilities. Soil structure and surrounding ground electrodes, as well as electrode surface and geometry, play a major role in configuring ground resistance values. In studying and designing the grounding systems of electric facilities with special specifications and demands, like High Voltage substations, wind farms, electric railways, etc., the dimensions and the geometry of the grounding system (grid, vertical rods, circumferential grounding by metallic strips and/or a combination of these electrodes) are usually standardized, depending on the construction type, or adjusted by the initial study, always according to the estimation of soil structure at the site of interest.

The detailed knowledge of the soil structure, in the territory where the project will be sited, is considered as an indispensable condition for the proper design of the respective grounding system. Hence, a first step of exceptional significance during the design of such systems is the determination of soil structure features, i.e., the number of soil layers and height and soil resistivity of each one of them. Soil resistivity measurements, performed by the High Voltage Lab of the National Technical University of Athens (NTUA), at various sites all over the country, have shown that earth presents a multilayer structure in the overwhelming majority of the tested cases. As a consequence of the multilayer soil structure, its modeling by suitable techniques is quite necessary for grounding design, i.e., the determination of the aforementioned soil structure features. There are numerous methodologies and developed algorithms in the international literature for the parameter estimation of two-layer soil models [5-9], three-layer soil models [10] and multilayer soil models [7,11-15] using soil resistivity measurements. In light of the experience gained from extended research reports and based on their results and findings, the authors have been urged to investigate the mechanism and the degree to which the randomness of selecting the measuring axes for soil resistivity affects the final measurement data. It is a substantial step before configuring the input data vectors introduced to the algorithm, aiming to minimize computational burden and algorithm diversion.

Soil resistivity measurements constitute the main input data vector in various software tools for the estimation of the multilayer soil parameters, and as a consequence, the errors in measurement, either because of the erroneous application of each measuring method, or because of the false choice of the measuring axes and the time period for the measurement, may lead to the false estimation of soil parameters and, therefore, to the defective design of a grounding system. Soil resistivity measurements with large uncertainty rates, furthermore, involve a large dispersion of values which, in turn, leads to a large computational burden, which is a particular difficulty in data mining and classification, as well as the probable local optimum entrapment of the algorithm and unacceptable errors. The present paper, based on the feedback from previous research works concerning the step and touch voltages developed around HV distribution substations [16] and the earth structure, along with the presence of ground enhancing materials surrounding ground electrodes affecting step voltage and ground resistance values [17], aims to highlight the sources of possible errors in measuring soil resistivity and the degree that they affect the soil model parameter estimation, as well the determination of the 
maximum permissible limits for step and touch voltages; this suggests that insufficient safety measures are possibly undertaken against faults.

\section{Soil Resistivity Measurement-Experimental Procedure}

Current flow through the earth is a necessary condition for measuring soil resistivity. This may happen only by driving vertical rods into the ground, supplied with electric current. Therefore, numerous techniques have been developed and proposed in the international literature, applied worldwide in grounding systems studies. The main ones referenced by international standards $[1,2]$ are: (a) the four-point method, (b) the three-point method and (c) the two-point method. The most frequently used method is the four-point method, which has several versions, as far as the four-electrode arrangement is concerned. The basic versions of this method are: (1) the Wenner method, (2) the Schlumberger-Palmer method, (3) the central electrode arrangement, (4) the Lee method, (5) the dipole-dipole method and (6) the square arrangement.

The most frequently used measuring method is the Wenner arrangement because of the simplicity of its application, this is the main reason that it was used for this study, and, therefore, the apparent resistivity was calculated by the respective equations of the Wenner arrangement [2], based on actual field measurements.

The study and design of a grounding system needs the necessary data of soil resistivity measurements. This requires, as already mentioned, the appropriate selection of (a) the measurement axes and (b) the season in which the measurement is to be conducted. Soil resistivity varies significantly during the year, depending on weather and climatic conditions. It would therefore seem necessary for engineers to measure soil resistivity in the summer months (referring to the northern hemisphere) or at the beginning of autumn in dry soil, thus, they would measure its maximum appearing values and, hence, the grounding system design would be regarded as safe.

In this study, soil resistivity measurements were performed in a large free field inside the university campus in the beginning of October 2017 in completely dry soil. All the measurements were performed on the same day in order to ensure that the measurement conditions would remain unchanged. The measurements were conducted upon eight (8) axes (namely a, b, c, d, e, i, ii and iii) with the arrangement shown in Figure 1. The probes were equally spaced at a distance $\alpha$ of $2 \mathrm{~m}, 4 \mathrm{~m}, 8 \mathrm{~m}, 12 \mathrm{~m}$ and $16 \mathrm{~m}$ at each axis, with the purpose of covering and capturing the earth structure in the whole testing field in the best possible way. The axes (a)-(e) were equally spaced at $5 \mathrm{~m}$, while the axes (i)-(iii) were approximately spaced at $15 \mathrm{~m}$. The places and the distances between the probes used for the Wenner method are illustrated along the central axis (c) in Figure 1.

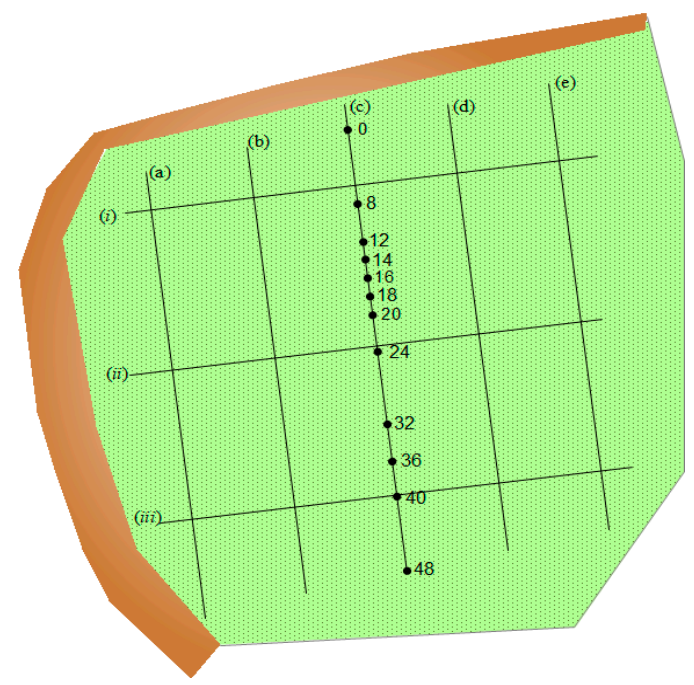

Figure 1. Measurement axes and probe distances. 
The number on each probe demonstrates its distance from the first one of the arrangement (0). Twelve auxiliary probes of $0.5 \mathrm{~m}$ in length were each driven into the earth to a depth of $0.4 \mathrm{~m}$ and, depending on the desirable measuring depth, four probes were used each time, e.g., for measuring a depth of $8 \mathrm{~m}$, the respective probe distance was $16 \mathrm{~m}$ and the measurement was carried out using the probes $0-16-32-48$. In this way, the apparent ground resistance in that terrain was measured at depths of $1 \mathrm{~m}, 2 \mathrm{~m}, 4 \mathrm{~m}, 6 \mathrm{~m}$ and $8 \mathrm{~m}$ on each measurement axis, then the respective apparent soil resistivity was calculated for each measuring depth and from each axis using Equation (1). The measurements were carried out by using the Auto Earth Tester (MEGGER DET2/2, Dover, Kent CT17, 9EN, England, 2007) with an operation frequency of $128 \mathrm{~Hz}$.

$$
\rho=\frac{4 \pi a R}{1+\frac{2 a}{\sqrt{\left(a^{2}+4 b^{2}\right)}}-\frac{a}{\sqrt{\left(a^{2}+b^{2}\right)}}}
$$

\section{Measurement Results and Determination of Multilayer Soil Models}

\subsection{Measurement Results—Discussion}

After measuring the apparent ground resistance at each axis and for the predetermined probe distances at each axis (i.e., eight (8) measurements for each distance $\alpha$ ), the respective apparent soil resistivity was calculated and the results are tabulated in Table 1 with the respective expanded uncertainty type A, considering a coverage factor of $95 \%$ [18] for each distance. The uncertainty $u_{A}$ is calculated for the measurement of soil resistivity at each depth considering the measurements from all the axes at the specific depth. Moreover, in this paper, the study for the variation of soil resistivity measuring value was conducted in terms of type A (random) uncertainty, since the measurement conditions remain unchanged, while the change in the position of the measuring axis substantially influences $u_{A}$, a component of combined standard uncertainty $\left(u_{c}(y)\right)$ [18]. A similar study on the measurement uncertainty of soil resistivity has been reported in the past [19], where the authors investigated and estimated the contribution of several factors, like soil temperature and humidity, measuring instrument, the depth of the measuring probes, the location of the measuring probes and the calculation of soil resistivity from the measured resistance to the measurement uncertainty. The variations of soil resistivity value $\rho$ for each measurement depth (i.e., probe distance), as well as the variation of the mean value $\rho_{m}$ from the eight axes at each depth, are subsequently captured with respect to the position of the measurement axis in Figure 2.

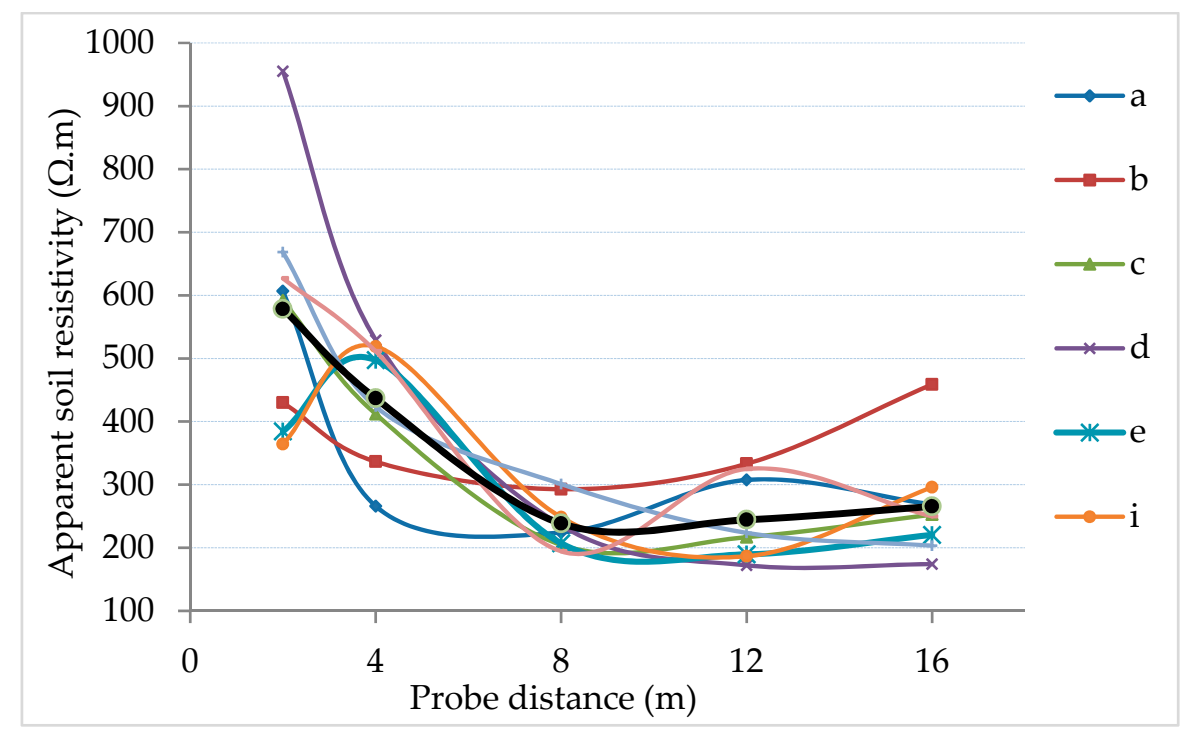

Figure 2. Soil resistivity variation versus probe distance for each measurement axis. 
Table 1. Apparent soil resistivity measurements $(\Omega . \mathrm{m})$ at the eight measurement axes.

\begin{tabular}{cccccccccc}
\hline $\boldsymbol{\alpha}(\mathbf{m})$ & (a) & (b) & (c) & (d) & (e) & (i) & (ii) & (iii) & $\mathbf{U}_{\mathbf{A}}(\%)$ \\
\hline 2 & 607 & 430 & 592 & 955 & 384 & 364 & 668 & 627 & 28.6 \\
4 & 266 & 336 & 412 & 529 & 497 & 519 & 424 & 511 & 18.9 \\
8 & 224 & 293 & 204 & 235 & 207 & 248 & 301 & 194 & 14.4 \\
12 & 307 & 333 & 217 & 172 & 190 & 187 & 224 & 325 & 23.4 \\
16 & 268 & 459 & 253 & 174 & 220 & 296 & 203 & 250 & 28.2 \\
\hline
\end{tabular}

The different variation rates of soil resistivity from axis to axis, as well the diversity in waveform shapes, are clear evidence of the strong heterogeneity of the testing field, expressed by sharp changes in $\rho$ values with respect to measurement depth and distances of a few meters between axes. Furthermore, it is obvious that the choice of the axis position causes significant deviation in the measured values of soil resistivity by the same probe distance-wise (i.e., in the same measurement depth). A typical case of this fact is the resistivity measurement at $\alpha=2 \mathrm{~m}$, where the maximum measuring value reaches the $955 \Omega \cdot \mathrm{m}$, the respective minimum value is $364 \Omega \cdot \mathrm{m}$, the deviation between them is in the order of $62 \%$, the sample standard deviation is $192 \Omega \cdot \mathrm{m}$ and the measurement uncertainty reaches $28.6 \%$ for a coverage factor of $95 \%$. The sample standard deviation for $a=4 \mathrm{~m}$ proportionally reaches $96 \Omega \cdot \mathrm{m}$, the second largest after that of $2 \mathrm{~m}$, while the measurement at $16 \mathrm{~m}$ presents similar uncertainty to that of $2 \mathrm{~m}$, reaching $28.2 \%$.

The large variance of the measurements in the upper soil layers, from place to place, also suggests the diversity in soil composition in the testing terrain, despite its relatively small surface area and the small distance between the axes. Moreover, the strong differences in soil composition appearing from place to place, yet in the same measuring layer, cause important increases in the measurement uncertainty of $\rho$ at a specific depth, for example, in the cases of $\alpha=2 \mathrm{~m}$ and $\alpha=16 \mathrm{~m}$. As a result, the mean value of the measurements for each depth, used for estimating the multilayer soil model, may largely deviate from the most representative resistivity value for each depth and the respective uncertainty consequently increases in the estimation of soil parameters.

\subsection{Calculation of Two-Layer and Three-Layer Soil Models}

\subsubsection{Description of the Calculation Process}

The variations in measuring values of $\rho$, resulting from the change in the measuring axis position, have a direct and tremendous impact on calculating soil parameters during the determination of the multilayer soil model. More specifically, the most commonly used soil models, for research and engineering purposes, according to [1,2], are the uniform soil model and the two-layer soil model. The latter constitutes a quite good approximation for several ground structures and a more accurate representation of the ground stratification and its conditions. On the basis of the above, it is clear that the uniform soil model would not be a good choice at all for representing the specific soil structure under study, since the ground in the testing terrain introduces a remarkable diversity in its structure. The two-layer soil model consists of the upper and the lower layer, with $\rho_{1}, h_{1}, \rho_{2}$ and infinite, and their resistivities and heights, where the values of these parameters are the result of the apparent soil resistivity measurement process with the aid of appropriate software tools.

For determining the two-, three-, or more generally, multilayer soil model at installation places of wind turbine generators, photovoltaic parks, HV substations, etc., measurements of apparent soil resistivity are taken on more than two measuring axes in the shape of a cross, or of a rectangle with one of its diagonals (five axes), depending on the required axes number, i.e., two, four or five, which is defined by the type of electric facility. The values of two-layer soil model parameters $\left(\rho_{1}, h_{1}, \rho_{2}\right)$ define, then, both the selection of the ground electrode geometry for reaching low resistance value, and the maximum permissible limits for step and touch voltages. Step and touch voltages must be suppressed 
below the permissible limits in designing a grounding system, for the safety of people working in or moving around the facilities.

The maximum permissible limits for step and touch voltages in a particular earth type, for a specific fault clearing time and for a human body of $70 \mathrm{~kg}$ in weight, are given by Equations (2) and (3) $[1,20]$ :

$$
\begin{aligned}
E_{\text {step70 }} & =\left(1000+6 C_{s} \times \rho_{s}\right) \frac{k}{\sqrt{t_{s}}} \\
E_{\text {touch70 }} & =\left(1000+1.5 C_{s} \times \rho_{s}\right) \frac{k}{\sqrt{t_{s}}}
\end{aligned}
$$

where $\rho_{s}$ is the resistivity of the surface material, $C_{s}$ is the surface layer derating factor given by an analytical expression [1] or other expressions under certain circumstances [20], $k$ is a coefficient with a value of 0.157 [1] or 0.091 [20] for a body weight of $70 \mathrm{~kg}$ and $t_{s}$ is the fault clearing time.

Five (5) groups, including a different combination of the predetermined measuring axes for each one of them, have been selected. Each one of the five testing groups, including a specific number of axes and, hence, soil resistivity measurements, was introduced to the used software package one at a time. The use of each group results in a different set of values for soil model parameters either for the two- or the three-layer soil model, thereby raising the importance of selecting the best axes layout for minimizing the estimation errors. The determined groups of measuring axes, namely 1,2 , 3, 4 and 5, include the following axis layouts: (1) a-c-e-i-iii, (2) b-d-i-ii-iii, (3) a-e-i-ii-iii, (4) b-c-d-i-iii and (5) a-b-c-d-e-i-ii-iii. The authors considered employing the suitable software suite SES/CDEGS for determining the two- and three-layer soil model parameters and the respective maximum permissible limits of step and touch voltages. The estimation of the permissible limits was realized for a current frequency of $50 \mathrm{~Hz}$, a body weight of $70 \mathrm{~kg}$, no surface material and a fault clearing time of $0.2 \mathrm{~s}$, $0.35 \mathrm{~s}$ or $0.5 \mathrm{~s}$. The value of $200 \mathrm{~ms}$ is considered adequate in light of the CIGRE TB 694 [20] relative recommendation for using a fault duration associated with primary protection. The authors also included the time values of $350 \mathrm{~ms}$ and $500 \mathrm{~ms}$, representative of the recommended typical range of 0.25-1.0 s., considering the recommendations of IEEE 80-2013 [1] and the requirements of the Greek Transmission System Operator for estimating short-circuit conditions with a clearance time of $500 \mathrm{~ms}$.

\subsubsection{Results and Discussion}

The simulation results are presented in Tables $2-5$, while the respective graphs are illustrated in Figures 3 and 4 .

The variations in the soil resistivity measurements of the upper ground layers at the testing field, which have been highlighted in a previous paragraph, are fully validated by the graph of Figure 3 a. The change in the measuring axis positions and the various combinations among them result in soil resistivity variance of the upper layer in the produced two-layer model. These variances, mainly in the $\rho_{1}$ value, are then reflected in the maximum permissible limits for both step and touch voltages (see Table 4 and Figure 4a), with those of the step voltages more prominent and, more obviously, for the shortest fault clearing times.

Similar variances in soil parameters values are also noted in the three-layer soil model (see Table 3 and Figure 3b). The variances in the measured resistivity values of the upper layers are reflected in the calculated values of soil resistivity for the upper and middle layers of the three-layer soil model, resulting in different estimated values for step and touch voltages, concerning alternative cases of the measuring axes (Table 5 and Figure $4 \mathrm{~b}$ ). It is observed that the two-layer soil model gives slightly higher values for step and touch voltage permissible limits for the axis cases 1, 2, 3 and 4 than the respective ones of the three-layer model, contrary to case 5 , where the three-layer model presents higher values for step and touch voltage limits than the two-layer model. It is noted that the soil models and the step and touch voltage limits presented in Tables 2-5 and Figures 3 and 4 are calculated on the basis of one-day measurements, a common practice applied in preliminary geotechnical studies of soil stratification for the design and construction of grounding systems. Thus, the selection of the 
measuring axes evidently affects the results of step and touch voltages, which, in turn, determine the potential extra technical precautionary measures and, therefore, the total cost of construction.

Table 2. Two-layer soil model parameters for the five combinations of resistivity measuring axes.

\begin{tabular}{cccc}
\hline Case & $\boldsymbol{\rho}_{\mathbf{1}}(\boldsymbol{\Omega} . \mathbf{m})$ & $\boldsymbol{\rho}_{\mathbf{2}}(\boldsymbol{\Omega} . \mathbf{m})$ & $\boldsymbol{h}_{\mathbf{1}}(\mathbf{m})$ \\
\hline 1 & 494.65 & 268.95 & 0.21 \\
2 & 571.27 & 285.48 & 0.78 \\
3 & 497.38 & 275.48 & 0.22 \\
4 & 580.58 & 287.19 & 0.22 \\
5 & 555.02 & 281.71 & 0.21 \\
\hline
\end{tabular}

Table 3. Three-layer soil model parameters for the five combinations of resistivity measuring axes.

\begin{tabular}{cccccc}
\hline Case & $\boldsymbol{\rho}_{\mathbf{1}}(\boldsymbol{\Omega} . \mathrm{m})$ & $\boldsymbol{\rho}_{\mathbf{2}}(\boldsymbol{\Omega} . \mathbf{m})$ & $\boldsymbol{\rho}_{\mathbf{3}}(\boldsymbol{\Omega} . \mathbf{m})$ & $\boldsymbol{h}_{\mathbf{1}}(\mathbf{m})$ & $\boldsymbol{h}_{\mathbf{2}}(\mathbf{m})$ \\
\hline 1 & 483.05 & 686.94 & 259.80 & 0.44 & 0.30 \\
2 & 571.27 & 592.73 & 288.31 & 0.37 & 0.26 \\
3 & 497.38 & 485.59 & 272.05 & 0.31 & 0.24 \\
4 & 556.94 & 592.25 & 281.59 & 0.39 & 0.26 \\
5 & 640.42 & 807.94 & 266.97 & 0.59 & 0.33 \\
\hline
\end{tabular}

Table 4. Maximum permissible limits for step and touch voltages from the two-layer soil model.

\begin{tabular}{|c|c|c|c|c|c|c|}
\hline \multirow{2}{*}{ Case } & \multicolumn{2}{|c|}{$200 \mathrm{~ms}$} & \multicolumn{2}{|c|}{$350 \mathrm{~ms}$} & \multicolumn{2}{|c|}{$500 \mathrm{~ms}$} \\
\hline & $E_{\text {step }}(\mathrm{V})$ & $E_{\text {touch }}(\mathrm{V})$ & $E_{\text {step }}(\mathrm{V})$ & $E_{\text {touch }}(\mathrm{V})$ & $E_{\text {step }}(\mathrm{V})$ & $E_{\text {touch }}(\mathrm{V})$ \\
\hline 1 & 1251.3 & 542.2 & 998.8 & 432.8 & 855.6 & 370.7 \\
\hline 2 & 1397.8 & 578.8 & 1115.7 & 462.0 & 955.8 & 395.8 \\
\hline 3 & 1256.5 & 543.5 & 1002.9 & 433.8 & 859.2 & 371.6 \\
\hline 4 & 1415.6 & 583.3 & 1129.9 & 465.5 & 967.9 & 398.8 \\
\hline 5 & 1366.7 & 571.0 & 1090.9 & 455.8 & 934.5 & 390.5 \\
\hline
\end{tabular}

Table 5. Maximum permissible limits for step and touch voltages from the three-layer soil model.

\begin{tabular}{|c|c|c|c|c|c|c|}
\hline \multirow{2}{*}{ Case } & \multicolumn{2}{|c|}{$200 \mathrm{~ms}$} & \multicolumn{2}{|c|}{$350 \mathrm{~ms}$} & \multicolumn{2}{|c|}{$500 \mathrm{~ms}$} \\
\hline & $E_{\text {step }}(\mathrm{V})$ & $E_{\text {touch }}(\mathrm{V})$ & $E_{\text {step }}(\mathrm{V})$ & $E_{\text {touch }}(\mathrm{V})$ & $E_{\text {step }}(\mathrm{V})$ & $E_{\text {touch }}(\mathrm{V})$ \\
\hline 1 & 1229.1 & 536.7 & 981.1 & 428.3 & 840.5 & 367.0 \\
\hline 2 & 1397.8 & 578.8 & 1115.7 & 462.0 & 955.8 & 395.8 \\
\hline 3 & 1256.5 & 543.5 & 1002.9 & 433.8 & 859.2 & 371.6 \\
\hline 4 & 1370.4 & 572.0 & 1093.8 & 456.5 & 937.0 & 391.1 \\
\hline 5 & 1529.9 & 611.9 & 1221.2 & 488.4 & 1046.1 & 418.4 \\
\hline
\end{tabular}

Another point of great interest in the study of soil models, produced from soil resistivity measurements upon various axes, is the selection criteria between uniform, two-layer and three-layer soil models. The selection criteria aim at the simplest possible representation of the earth structure at the installation site of a grounding system, yet without any loss of accuracy. 


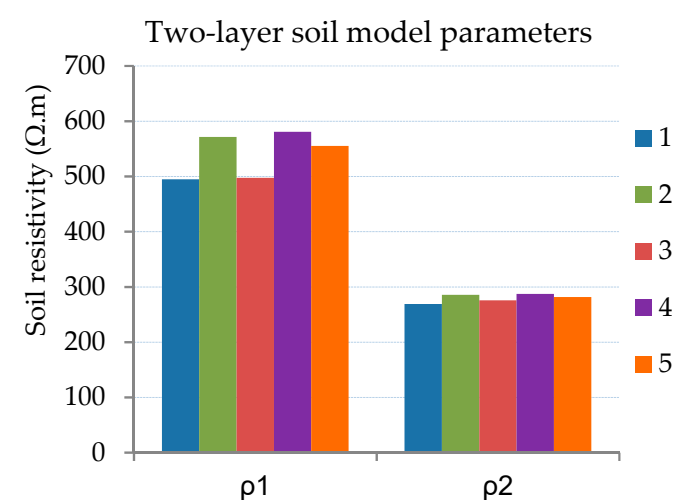

(a)

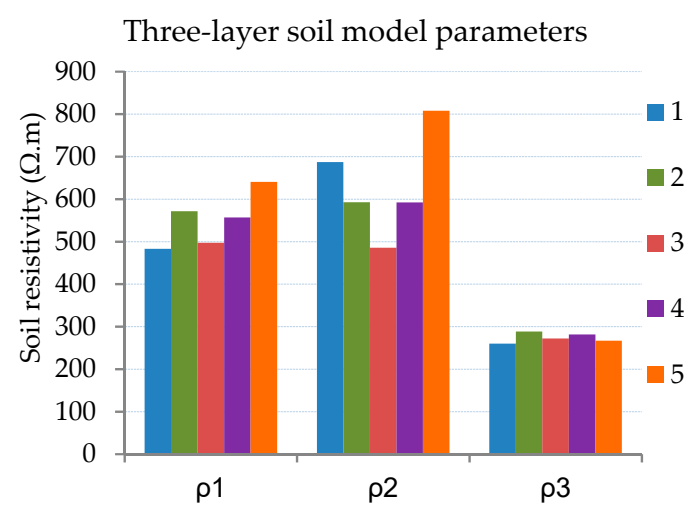

(b)

Figure 3. (a) Variation of the two-layer soil model parameters with respect to the resistivity measuring axes (see Table 2); (b) variation of the three-layer soil model parameters with respect to the resistivity measuring axes (see Table 3).

Step and touch voltage limits

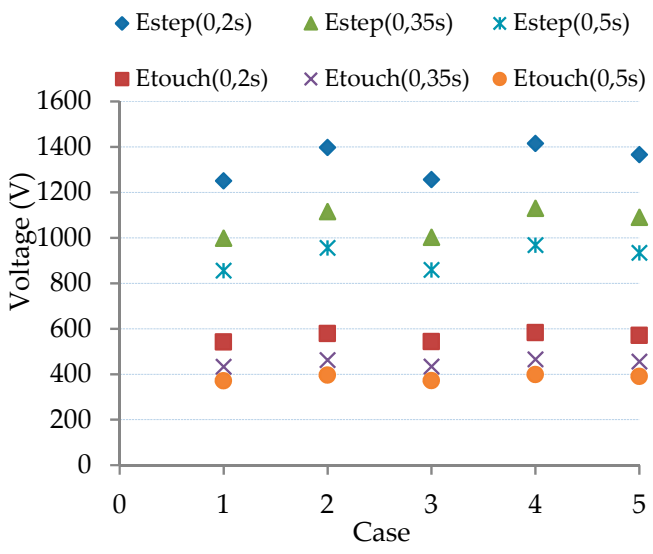

(a)

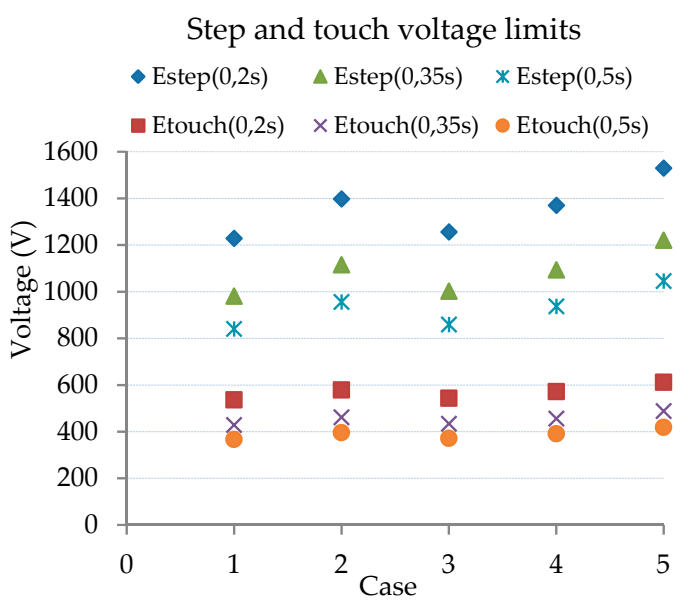

(b)

Figure 4. (a) Variation of the maximum permissible limits for step and touch voltages with respect to the resistivity measuring axes (two-layer); (b) variation of the maximum permissible limits for step and touch voltages with respect to the resistivity measuring axes (three-layer).

The problem of properly choosing one model or the other is the identified weakness of some algorithms and commercial software packages in the market-most commonly used by engineers and technical companies for studying and designing grounding systems-to calculate three-layer or multilayer soil models. This is a very crucial point, because as a consequence, the grounds at plenty of critical sites are not possible to be represented with good accuracy by uniform or two-layer soil models, like mountain ridges and plateaus, where the soil stratification may consist of thick bedded limestone with karst features, volcanic rocks, aluminate precipitate and sandy soil. The unquestioning adoption of uniform or two-layer soil models, under such complex soil circumstances, where a multilayer soil model could give satisfactory and accurate results, entails risks inherent in estimating erroneously the maximum permissible limits and, hence, incorrectly designing the grounding system. It has to be noted, at this point, that some software packages automatically choose the type of soil model, after a series of calculations, for the approximation of earth structure in designing grounding systems. Nevertheless, even in that case, the experience and the serious attention of engineers are absolutely necessary.

In addition to the problem of soil structure in choosing the appropriate soil model, there is also the environmental factor, effecting on the voltage values produced by each model. More specifically, from a series of measurements and simulations, it was observed that the improper soil model for the 
representation of a soil structure is more vulnerable to changing weather conditions, which gives extremely variable values for step and touch voltages limits, which have no sense in the grounding system design.

The graphs in Figure 5 are a clear example of this claim. These graphs were yielded from a series of measurement data for apparent soil resistivity in the testing field, upon a single axis (c), collected from the High Voltage Lab of NTUA over a long period of time in the context of a research project. The soil resistivity measurements were performed almost every day for the time period referred to in the graphs under variable rainfall conditions. The variances in the maximum permissible limits for step and touch voltages are captured in the graphs of Figure 5, as they were calculated using twoand three-layer soil models in the period 16 October 2015-18 January 2016. The permissible limits were estimated for a current frequency of $50 \mathrm{~Hz}$, a body weight of $70 \mathrm{~kg}$, no surface material, a surface material of resistivity $2500 \Omega \cdot \mathrm{m}$ (gravel) and 10,000 $\Omega \cdot \mathrm{m}$ (asphalt) and a fault clearing time of $0.5 \mathrm{~s}$. The graphs $5 \mathrm{a}$ and $5 \mathrm{~b}$ are drawn for the case of no surface material, $5 \mathrm{c}$ and $5 \mathrm{~d}$ are for the material of $2500 \Omega \cdot m$, and finally $5 \mathrm{e}$ and $5 \mathrm{f}$ for the material of $10,000 \Omega \cdot \mathrm{m}$.

The selection of the appropriate model is proved to be of paramount importance each time for the most accurate approximation of soil structure, according to Figure 5. The maximum deviation between the step voltage values given by the two models reaches the percentage of $53 \%$ in the case of no surface material in mid-October, while the mean deviation reaches $33 \%$ in the period considered. For the touch voltage, accordingly, the maximum deviation reaches $33 \%$, while the mean deviation ranges around $18 \%$. Adopting the two-layer soil model for the specific ground type leads to an overestimation of the maximum permissible limits for the voltages considered and, consequently, to the incomplete and possibly dangerous design of grounding systems. It is certainly worth mentioning that the addition of surface material significantly reduces the deviation in voltage estimation between the two models and obviously stabilizes the fluctuation in limit values of each single model. By way of illustration, the mean deviation between the step voltage values ranges around $1 \%$ in the case of surface material with a $\rho_{c}=10,000 \Omega \cdot \mathrm{m}$.

The high variance of the maximum permissible limits—by the two-layer soil model—is also remarkable, unlike the three-layer model which demonstrates very good stability in values. This reflects, to a large extent, the fact that the upper layer occupies different height between the two models. The upper layer is higher in the two-layer model $(0.8-1.5 \mathrm{~m})$ than the one in the three-layer model $(0.3-0.5 \mathrm{~m})$ and involves ground layers with different moisture contents at the time of measurement, i.e., different relative humidity between the ground surface layer and the layer near to $1.5 \mathrm{~m}$. This, therefore, means that the rate of change of humidity varies largely from layer to layer between those constituting the upper layers of the two-layer model. These large differences in humidity, appearing inside the upper layer of the two-layer model, in conjunction with the variable soil composition in the upper layer due to its height, result in large variances in step and touch voltage permissible limits on the one hand, and an overestimation of those values on the other hand. A noteworthy feature is that the overestimation of step and touch voltage limits may lead to a devaluation of the necessary extra protective measures that must be taken (e.g., the extent of grounding mesh, extra vertical grounding rods) for reasons of cost savings against safety, as is shown in Figure 5a in the case of the two-layer soil model. Instead, the large underestimation of step and touch voltage limits may lead to unnecessary and cost-intensive protective measures, significantly increasing the project budget. 


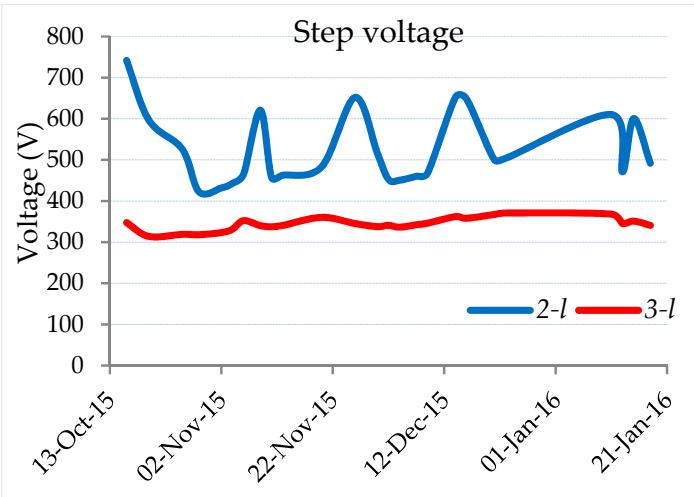

(a)

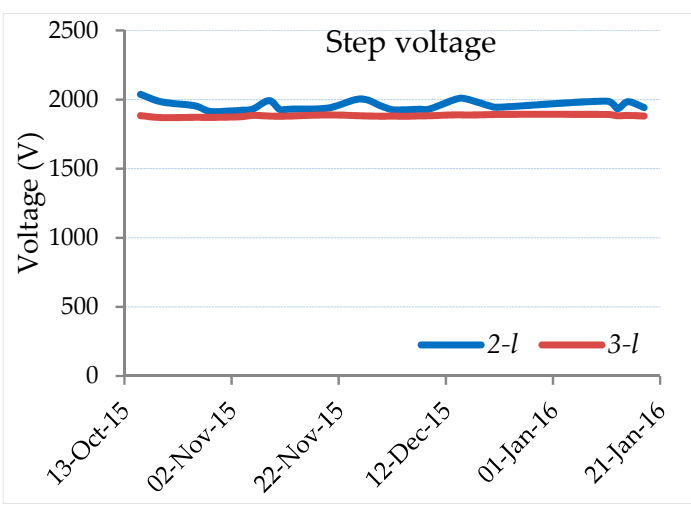

(c)

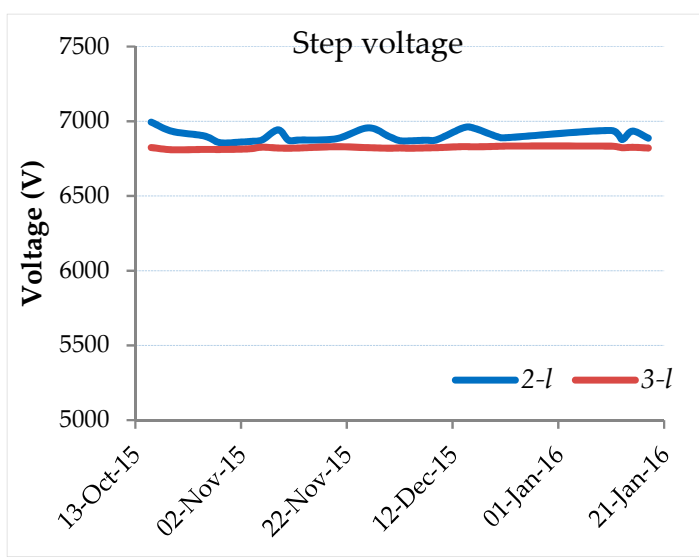

(e)

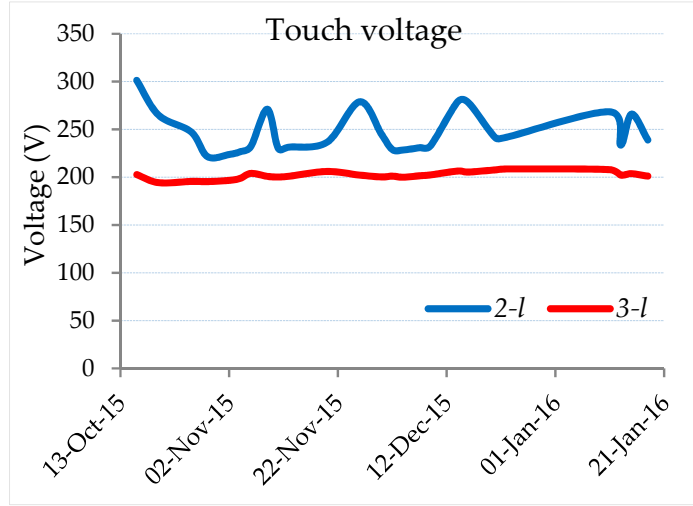

(b)

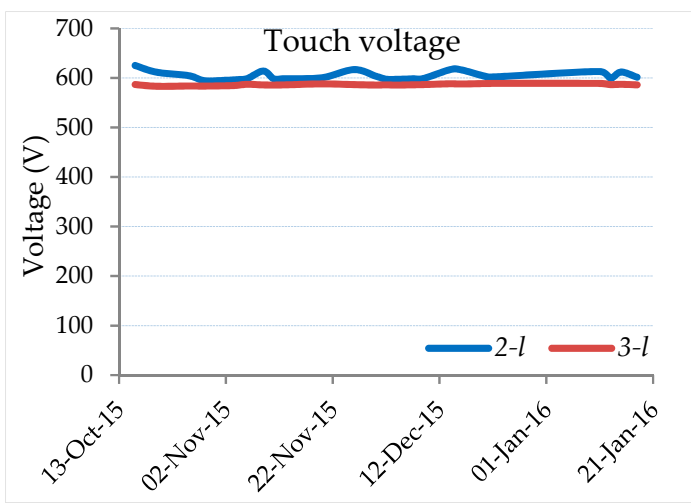

(d)

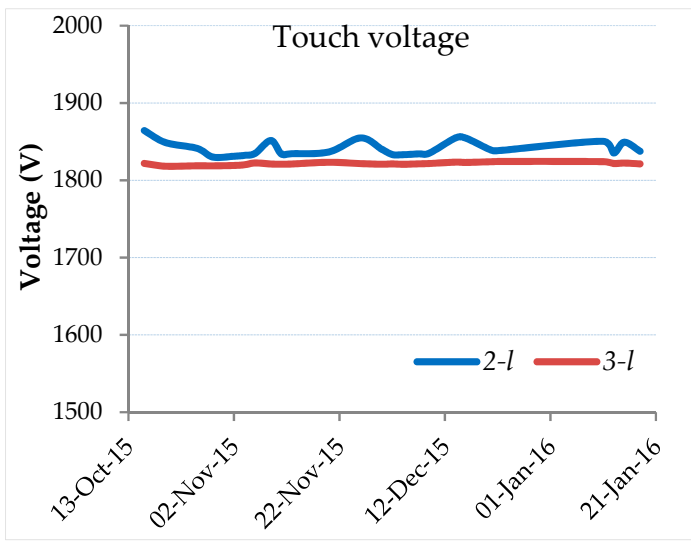

(f)

Figure 5. Variation of the maximum permissible limits for step and touch voltage as a function of time (blue line: two-layer soil model, red line: three-layer soil model): $(\mathbf{a}, \mathbf{b})$ Step and touch voltage with no surface layer, (c,d) step and touch voltage for surface layer of $2500 \Omega \cdot m$ (gravel), (e,f) step and touch voltage for surface layer of $10,000 \Omega \cdot \mathrm{m}$ (asphalt) with a surface layer thickness of $10 \mathrm{~cm}$. 


\subsubsection{Soil Resistivity Measurement Guidelines}

Considering the above results for soil model parameters, and step and touch voltages produced from the various axis locations, some useful guidelines may be referred to for the appropriate selection of measuring axes and the suitable soil model for each case. The number and the location of the axes are mainly dependent on the grounding grid configuration, the maximum permissible limit for the ground resistance value, as far as the electric facility is concerned and, certainly, the deviation among the measured values at the same depth. The probe distance may vary depending on the depth at which the soil profile knowledge is required. The practice the authors usually follow at the various locations is the soil resistivity measurement along five (5) axes with a maximum probe distance $(\alpha)$ of $20 \mathrm{~m}$. Yet, this probe distance should increase in the case that the measured resistivity value increases with the probe distance. As a next step, the calculation of the mean value and the standard deviation of the measurement results for each probe distance should be considered. If the percentage deviation is greater than $10 \%$, the measurement should be performed at more axes, with an upper limit of 12 axes. It is important to carry out the measurements on dry soil where no precipitation has been occurred at least four days before the measurement. In regards to the soil model selection, the respective solver of the used software calculates a series of multilayer soil models (uniform, two-, three- and multilayer models) for the terrain of interest and the calculated one with the lower Root Mean Square (RMS) error value is finally selected.

\section{Conclusions}

In the present study, an effort has been made to highlight the great importance of properly applying the measuring methods of soil resistivity and, principally, appropriately selecting the measuring axes. For this purpose, apparent soil resistivity measurements were carried out in a large testing terrain inside the university campus, using the Wenner method at various depths and upon eight (8) different measuring axes covering the area considered. Then, the measured resistivity values from axis to axis at the corresponding depths were compared to each other. A detailed and in-depth analysis was made for both the resistivity variation (with respect to the measuring axis position) and the repercussions of this variation on estimating the parameters of multilayer soil models in conjunction with the measurement uncertainty.

Furthermore, the maximum permissible limits for step and touch voltages were estimated and the impact of soil resistivity variation on these limits was thoroughly investigated. Diligent study for selecting the position and the number of measuring axes for soil resistivity measurement at the electric facility site and the proper application of each measuring method play a major role in the accurate and reliable representation of the real earth structure and guarantee the complete and safe design of grounding systems. This fact is fully confirmed by the maximum permissible voltage values that emerged from each axis combination. The main concern of engineers developing algorithms for parameter estimation in soil models and ground resistance estimation is the computational burden they have to tackle, the convergence level and the estimation accuracy. The issue of resistivity measurement data with large uncertainty boundaries, raised by the results of this work, if carefully addressed at the starting stage of the measurements, will boost each used computational and optimization algorithm to inconceivable speed and estimation accuracy. The results of this study may be a useful guide for obtaining, pre-selecting and pre-processing the appropriate measurement data for configuring the needed input data vectors.

Finally, there was an analysis of the degree to which the selection of two- or three-layer soil models affect the estimation of maximum permissible limits for step and touch voltages on specific ground types, like the one in the testing field. The results have shown that the uniform and the two-layer soil models are not a panacea for all the particularities demonstrated by the various earth structures. The grounding system design should not count exclusively on these two models since this action could probably result in overestimating the maximum permissible limits and put people's safety in 
jeopardy in the case of a fault. The layer number in a multilayer model must be selected after a careful evaluation of the simulation results and the selection proposed by the designing software.

Author Contributions: Conceptualization-methodology, V.P.A., K.D.D. and I.F.G.; validation—software, K.D.D.; writing-review and editing, V.P.A., K.D.D., C.A.C. and I.F.G.; supervision, I.F.G. and C.A.C.; project administration, I.F.G. All authors have read and agreed to the published version of the manuscript.

Funding: This research received no external funding.

Conflicts of Interest: The authors declare no conflict of interest.

\section{References}

1. IEEE. IEEE Guide for Safety in AC Substation Grounding. IEEE Stand. 80-2013, 1; IEEE: New York, NY, USA, 2013. [CrossRef]

2. IEEE. IEEE Guide for Measuring Earth Resistivity, Ground Impedance, and Earth Surface Potentials of a Grounding System. IEEE Stand. 81-2012; IEEE: New York, NY, USA, 2012. [CrossRef]

3. Smohai, B.; Ladanyi, J. Auxiliary electrode arrangements' Effect on earth resistance measurements with fall-of-potential method. EEA-Electroteh. Electron. Autom. 2014, 62, 93-100.

4. Smohai, B.; Ladanyi, J. The inductive coupling among leads while measuring resistance to earth of transmission line towers. EEA-Electroteh. Electron. Autom. 2015, 63, 60-67.

5. Meliopoulos, A.P.; Papalexopoulos, A.D. Interpretation of soil resistivity measurements: Experience with the model SOMIP. IEEE Trans. Power Deliv. 1986, 1, 142-151. [CrossRef]

6. Seedher, H.R.; Arora, J.K. Estimation of two layer soil parameters using finite Wenner resistivity expressions. IEEE Trans. Power Deliv. 1992, 7, 1213-1217. [CrossRef]

7. Gonos, I.F.; Stathopulos, I.A. Estimation of multilayer soil parameters using genetic algorithms. IEEE Trans. Power Deliv. 2005, 20, 100-106. [CrossRef]

8. Gonos, I.F.; Kontargyri, V.T.; Stathopulos, I.A.; Moronis, A.X.; Sakarellos, A.P.; Kolliopoulos, N.I. Determination of two layer earth structure parameters. In Proceedings of the XVII International Conference on Electromagnetic Disturbances (EMD 2007), Bialystok, Poland, 19-21 September 2007; pp. 19-21.

9. Papadopoulos, T.A.; Ceylan, O.; Papagiannis, G.K. Two-layer earth structure parameter estimation and seasonal analysis. In Proceedings of the 53rd International Universities Power Engineering Conference (UPEC 2018), Glasgow, Scotland, UK, 4-7 September 2018.

10. Yang, H.; Yuan, J.; Zong, W. Determination of three-layer earth model from Wenner four-probe test data. IEEE Trans. Magn. 2001, 37, 3684-3687. [CrossRef]

11. Takahashi, T.; Kawase, T. Analysis of apparent resistivity in a multi-layer earth structure. IEEE Trans. Power Deliv. 1990, 5, 604-612. [CrossRef]

12. Calixto, W.P.; Neto, L.M.; Wu, M.; Yamanaka, K.; Moreira, E.D.P. Parameter estimation of a horizontal multilayer soil using genetic algorithm. IEEE Trans. Power Deliv. 2010, 25, 1250-1257. [CrossRef]

13. Pereira, W.R.; Soares, M.G.; Neto, L.M. Horizontal multilayer soil parameter estimation through differential evolution. IEEE Trans. Power Deliv. 2016, 31, 622-629. [CrossRef]

14. Jesenik, M.; Mernik, M.; Črepinšek, M.; Ravber, M.; Trlep, M. Searching for soil models' parameters using metaheuristics. Appl. Soft Comput. 2018, 69, 131-148. [CrossRef]

15. Yang, J.; Zou, J. Parameter estimation of a horizontally multilayered soil with a fast evaluation of the apparent resistivity and its derivatives. IEEE Access 2020, 8, 52652-52662. [CrossRef]

16. Poulimenos, G.; Damianaki, K.D.; Christodoulou, C.A.; Androvitsaneas, V.P.; Gonos, I.F. Examination of the effectiveness of the grounding systems of distribution substations. In Proceedings of the 2018 IEEE International Conference on High Voltage Engineering and Applications (ICHVE 2018), Athens, Greece, 10-13 September 2018.

17. Tao, Y.; Wei, J.; Li, Q.; Shi, Y.; Zhang, T.; Zhang, J.; Liu, X. The effect of a large backfill area on grounding grid performance. Energies 2018, 11, 698. [CrossRef] 
18. ISO/IEC Guide 98-4:2012, Uncertainty of measurement-Part 4: Role of measurement uncertainty in conformity assessment. 2012. Available online: https://isotc.iso.org/livelink/livelink/fetch/2000/2122/423045 0/8389141/ISO_IEC_Guide_98-4_2012\%28E\%29_-_Uncertainty_of_measurement_--_Part_4\%2C_Role_of _measurement_uncertainty_in_conformity_assessment.pdf?nodeid=14831662\&vernum=-2 (accessed on 31 May 2020).

19. Berlijn, S.; Halsan, K.; Gärtner, T. The measurement uncertainty in and practicality of measurement of soil resistivity and grounding resistance. In Proceedings of the 15th International Symposium on High Voltage Engineering (ISH 2007), Ljubljana, Slovenia, 27-31 August 2007.

20. CIGRE. TB 694-2017, Ground potential rise at overhead AC transmission line structures during power frequency faults. 2017. Available online: https://e-cigre.org/publication/694-ground-potential-rise-at-overh ead-ac-transmission-line-structures-during-power-frequency-faults (accessed on 31 May 2020).

C 2020 by the authors. Licensee MDPI, Basel, Switzerland. This article is an open access article distributed under the terms and conditions of the Creative Commons Attribution (CC BY) license (http://creativecommons.org/licenses/by/4.0/). 